\title{
O plano de ações articuladas no contexto do federalismo brasileiro: instrumento de colaboração intergovernamental?*
}

\author{
The articulated actions plan in the context of Brazilian federalism: \\ intergovernmental collaboration device?
}

\author{
Plan de acciones articuladas en el contexto del federalismo brasileño: \\ instrumento de colaboración intergubernamental?
}

\author{
DANIELA CUnHa TERTO** \\ Alda MARIA DUARTE ARAÚJO CASTRO*** \\ HIRONOBU SANO****
}

\begin{abstract}
RESUMO
O artigo discute o Plano de Ações Articuladas (PAR) no contexto do federalismo brasileiro. Seu objetivo é analisar se o referido plano tem favorecido a colaboração intergovernamental no campo educacional, em consonância com o regime federativo cooperativo, o qual pressupõe relações intergovernamentais interdependentes. A pesquisa bibliográfica e documental revelou que, ainda que o PAR tenha favorecido a interação das equipes do MEC com as secretarias locais, bem como a coordenação federativa exercida pelo governo federal, não é possível afirmar que o plano tenha sido capaz de efetivar a colaboração intergovernamental no campo educacional brasileiro. Isso porque a colaboração vai além da coordenação ao requerer o compartilhamento das tomadas de decisões e o exercício conjunto das competências compartilhadas.

Palavras-chave: Planejamento educacional. Relações intergovernamentais. Federalismo cooperativo.
\end{abstract}

\begin{abstract}
In this article, a discussion about the Articulated Actions Plan (AAP), within the Brazilian federalism context, is proposed, as it is intended as a way to analyze whether the mentioned plan has eased the intergovernmental collaboration in the educational field, and whether this plan is in accordance with the federal government system. Bibliographic and documentary researches revealed that, although the AAP facilitated the interaction between the Brazilian Ministry of Education teams and local boards as well as the federal coordination, which is managed by the federal Government, it is not possible to say that the APP has been able to make intergovernmental cooperation in the educational field effective.
\end{abstract}

Keywords: Articulated actions plan. Federalism. Intergovernmental relations.

\section{RESUMEN}

Este artículo discute el Plan de Acciones Articuladas (PAR) en el contexto del federalismo brasileño. Su objetivo es analizar si el referido Plan está auxiliando la colaboración intergubernamental en el campo educacional, en harmonía con el régimen federativo cooperativo, que presupone relaciones intergubernamentales interdependientes. La investigación bibliográfica y documental ha revelado que si bien el PAR auxilia la interacción de los equipos del MEC con las secretarías locales como también la coordinación federativa ejercida por el gobierno federal, no es posible afirmar que el Plan ha sido capaz de asegurar la colaboración intergubernamental en el campo educacional brasileño, puesto que la colaboración va más allá de la coordinación, por requerir coparticipación en las decisiones y el ejercicio conjunto de las competencias compartidas.

Palabras clave: Planeamiento educacional. Relaciones intergubernamentales. Federalismo cooperativo.

\footnotetext{
*Este trabalho é parte de uma pesquisa em rede denominada "Avaliação do Plano de Ações Articuladas - PAR (2007-2011): um estudo em municípios do Rio Grande do Norte, Pará e Minas Gerais", financiada pelo Observatório da Educação, da Coordenação de Aperfeiçoamento de Pessoal de Nível Superior (Capes)/Ministério da Educação (MEC) - Edital no 049/2012.

**Possui graduação em Pedagogia e mestrado em Educação cursados na Universidade Federal do Rio Grande do Norte. Atualmente cursa o doutorado em Educação na mesma instituição. E-mail: <danielaterto@gmail.com>.

*** Doutora em Educação. Professora do Departamento de Fundamentos e Políticas da Educação e do Programa de Pós-Graduação em Educação da Universidade Federal do Rio Grande do Norte.E-mail: <aldacastro01@hotmail.com>.

****Doutor e mestre em Administração Pública e Governo pela Fundação Getúlio Vargas/SP. E-mail: <hiro.sano@gmail.com>.
} 


\section{INTRODUÇÃO}

O cenário educacional brasileiro tem sido marcado por profundas diferenças entre os sistemas de ensino, Inter e inter-regionais. Historicamente, desde a colonização do território brasileiro, as desigualdades regionais e educacionais têm sido marcas de nossa formação. Tais características permaneceram nos períodos subsequentes, e na atual República ainda representam um desafio. Desse modo, a consolidação do direito à educação pública, gratuita e de qualidade a todos os brasileiros mantém-se como uma conquista a ser alcançada.

Em 2007, o governo federal lançou o Plano de Desenvolvimento da Educação (PDE), cujo principal objetivo era melhorar a qualidade da educação brasileira em todos os níveis e modalidades. O PDE é operacionalizado pelo Decreto 6094, de 24 de abril de 2007, o qual dispõe sobre a implementação do Plano de Metas Compromisso Todos pela Educação. Esse plano fixa 28 diretrizes como metas para a melhoria da qualidade da educação a serem alcançadas por meio da colaboração entre os entes federados, bem como da participação das famílias e da comunidade.

Visando ao cumprimento das metas do compromisso, em seu Art. $9^{\circ}$, o decreto cria o Plano de Ações Articuladas (PAR), instrumento de planejamento e de gestão realizado pelos municípios com o objetivo de receber assistência técnica e financeira da União para a execução de ações que contribuam para a melhoria da educação. É no âmbito do Plano de Ações Articuladas que este trabalho está inserido, pretendendo analisar se o PAR tem favorecido a cooperação intergovernamental entre os entes federados, em consonância com o arranjo federativo brasileiro. Trata-se de uma discussão pertinente, haja vista a interdependência cada vez mais necessária entre os entes federativos para a implementação de políticas públicas nas áreas sociais, sobretudo no que se refere à educação, em razão das competências comuns aos três níveis de governo da federação brasileira, bem como da função supletiva da União nessa área.

Para alcançar esse objetivo, além desta introdução, este trabalho está dividido em quatro seções. Nas duas primeiras, tem-se uma breve revisão da literatura na qual se destacam como categorias de análise os temas federalismo e relações intergovernamentais. Trata-se de uma fundamentação teórica relevante para análise das políticas educacionais no cenário educacional brasileiro, considerando que "[...] é muito difícil entender o atual modelo educacional e buscar seu aperfeiçoamento sem compreender a dinâmica federativa" (ABRUCIO, 2010, p. 39).

Em seguida, apresenta-se e discute-se o Plano de Ações Articuladas, para, na sequência, analisá-lo à luz dos conceitos discutidos na seção teórica, a fim de se identificar se o este tem favorecido a cooperação intergovernamental em conformidade com o regime federativo. Na última parte, apontam-se as considerações finais sobre o trabalho empreendido.

\section{FEDERALISMO: CONCEITO E NATUREZA}

O federalismo é uma forma de organização políticoterritorial na qual coexistem diferentes níveis de governo que gozam de autonomia. Difere das outras formas de organização por ser constituído pela descentralização do poder e não pela soberania absoluta por parte de um único governo. Pode ser caracterizado como um pacto entre as unidades governamentais de uma nação, conforme esclarece Elazar:

o termo 'Federal' é derivado do latim foedus, que [...] significa aliança. Em essência, um arranjo federativo é de parceria, estabelecida e regulada por um pacto, cujas relações internas refletem o tipo especial de partilha que deve prevalecer entre os parceiros, com base no reconhecimento mútuo da integridade de cada parceiro e a tentativa de promover uma unidade especial entre eles (1987, p. 5, tradução dos autores).

Para esse autor, o federalismo é um pacto, um tratado de confiança e de respeito estabelecido entre os entes, e a tese central dos regimes federativos é a combinação de autogoverno e governo partilhado. Assim, cada governo mantém suas regras próprias concomitantemente à existência de regras comuns e compartilhadas entre os distintos governos. Esse fato aponta para uma característica fundamental de sistemas federais: a existência de unidades federadas distintas com autonomia para formular políticas próprias, bem como capacidade para influenciar na formulação das políticas advindas do governo central.

Elazar defende o princípio da não centralização de poder para analisar a relação entre os entes que formam uma federação. De acordo com o autor, no regime federalista não centralizado, os poderes do governo são difundidos entre muitos centros, cujas existência e autoridade são garantidas pela constituição geral, em vez de se concentrarem em um único centro (ELAZAR, 1987). Observa-se que nos regimes federados não há a existência de um único centro de poder, mas sim de múltiplos centros que se interconectam por uma lei respeitada e compartilhada pelas partes.

Apesar de este artigo estar fundamentado na teoria do federalismo como pacto, vislumbram-se seus limites. Concorda-se com Souza (2008) no sentido de que um dos possíveis limites presentes nessa concepção é a 
possibilidade de se negar o caráter conflituoso e instável na relação entre os governos autônomos:

ao tratar a opção complexa do federalismo como um pacto e não como uma barganha em constante evolução, [...] essa linha teórica encobre o caráter altamente conflituoso e instável que marca esse sistema de divisão territorial de autoridade e de governo e apresenta o federalismo como uma situação de equilíbrio entre forças opostas - união versus autonomia, centralização versus descentralização e regra da maioria para preservar a unidade versus direitos das minorias para preservar a diversidade (SOUZA, 2008, p. 32).

O equilíbrio entre as forças opostas citadas pela autora e que é regido pelos princípios de autonomia e interdependência nem sempre revela uma situação de estabilidade na realidade dos países federados. A interrelação entre os distintos níveis de governo não elimina a possibilidade de conflito entre eles e nem a predominância de uma instância sobre a outra, em certas situações e momentos históricos em que determinadas unidades de governo ocuparão mais espaços nas arenas de tomadas de decisão.

Grodzins (1966) estabelece o conceito de federalismo cooperativo. Este é um desdobramento do federalismo como pacto e inclui em sua análise a dinâmica do relacionamento entre os governos, considerando que está nem sempre será harmoniosa e de modo algum estática. Entretanto, a cooperação entre as instâncias governamentais é elemento necessário ao desenvolvimento das federações e está fundamentada nos acordos e barganhas entre seus níveis de governo.

A inter-relação entre os entes federados é um elemento primordial dentro dos regimes federativos, sendo fundamental a compreensão da dinâmica federativa na qual essa relação nem sempre significará harmonia. Por vezes, pode até ser antagônica ou mesmo forçada por uma determinada situação dentro da federação. O que não está previsto em um regime federal é a total separação e isolamento entre as partes, como destaca Franzene (2010, p. 38):

[...] observa-se que o adjetivo cooperativo não implica uma interação tranquila e amigável entre as esferas de governo, como poderia sugerir o nome. Quer dizer apenas que os diferentes governos devem funcionar e trabalhar juntos - não por opção, mas pela própria dinâmica estabelecida pelo desenho constitucional federativo.

Essa dinâmica nunca será estática ou padronizada, e dentro da trama que é a cooperação entre os entes os arranjos federativos assumem formas distintas e obtêm efeitos distintos, de acordo com o desenho institucional traçado. Assim, a barganha entre os níveis de governo faz parte do sistema federativo, de modo que cada ente tende a tirar o maior proveito dessa relação.

Ademais, alguns entraves podem ser encontrados no federalismo cooperativo. As relações verticais estabelecidas entre os entes, por vezes, podem ser confundidas, ou até mesmo desenhadas, de modo a configurarem-se como verticalização, pendendo essa relação mais para a subordinação do que para a cooperação.

Essas ações tendem a enfraquecer o regime federativo, devendo-se primar por relações intergovernamentais que estejam fundadas na cooperação, como observa Abrúcio (2005, p. 43, grifo do autor): "O fato é que a soberania compartilhada só pode ser mantida ao longo do tempo caso se estabeleça uma relação de equilíbrio entre a autonomia dos pactuantes e sua interdependência".

É nesse sentido que se dá continuidade aos estudos neste artigo, buscando compreender as relações intergovernamentais e como estas se configuram dentro do regime federativo.

\section{FEDERALISMO E RELAÇõES INTERGOVERNAMENTAIS}

As recentes obras que discutem o federalismo têm realizado a discussão, incluindo o debate sobre as relações intergovernamentais, quer seja verticalmente, no âmbito das relações estabelecidas entre União, estados e municípios, quer seja horizontalmente, entre entes do mesmo nível de governo (SANO, 2008; ABRUCIO, 2005).

O termo relação intergovernamental "[...] pretende designar um importante corpo de atividades e interações que ocorrem entre unidades governamentais de todos os tipos e níveis dentro do sistema federal" (WRIGHT, 1988, p. 14, tradução dos autores). Um avanço nessa compreensão diz respeito às formas de interação entre os níveis de governo, as quais podem ser tanto horizontais quanto verticais.

Wright (1988) elencou três tipos distintos de relações intergovernamentais. O modelo de autoridade independente caracteriza-se por ser uma relação de total independência ou autonomia entre os diferentes níveis de governos, sem necessidade, portanto, de interlocução entre as partes. Já o modelo de autoridade inclusiva ou hierárquica é exemplificado quando a atuação dos governos subnacionais depende das decisões tomadas pelo governo central. Nesse modelo, estados e municípios assemelham-se mais com unidades administrativas do governo central do que como entes autônomos. As relações intergovernamentais são essencialmente baseadas em 
um conjunto hierárquico de relações e salientam o papel predominante do nível nacional. O terceiro modelo, o de autoridade interdependente ou sobreposta, é caracterizado pela relação de interdependência e compartilhamento entre os entes e apresenta três características: as áreas significativas das operações governamentais envolvem as unidades nacional, estaduais e locais, simultaneamente; as áreas de autonomia ou jurisdição única e de independência e total liberdade são comparativamente menores; o poder e a influência disponíveis para qualquer uma das jurisdições, individualmente, são significativamente limitados, sendo que esses limites produzem um padrão de autoridade que é mais bem descrito como barganha (WRIGHT, 1988). Assim, um aspecto central nesse modelo é a prevalência da barganha, relacionando-se com o federalismo cooperativo.

$\mathrm{O}$ modelo de autoridade interdependente de Wright provê uma base conceitual para compreensão das relações intergovernamentais para além de um modelo estático e rígido, realçando o papel da barganha entre os diferentes níveis de governo, bem como a complexidade dessa relação. Essa dinâmica acentua-se ainda mais nos países cujo sistema de governo é o federalismo, o qual demanda uma relação constante de negociação entre os entes federados e que busca sempre o equilíbrio na relação entre as regras comuns e as regras próprias de cada governo.

Esse modelo de relações intergovernamentais é aquele que mais se aplica à abordagem do federalismo como pacto, no qual predominam a negociação e a barganha entre as unidades governamentais, em detrimento de uma relação de subordinação. Nesse sentido, Wright (1988) destaca que o modelo de sobreposição de autoridade postula relações intergovernamentais enquanto relações modeladas, cujos comportamentos são interdependentes e negociados entre as autoridades nacionais, estaduais e locais. Os contatos e trocas entre os funcionários dos governos podem ser simultaneamente cooperativos e competitivos; os fatores determinantes para tanto podem incluir a questão política, o status dos funcionários (eleitos ou nomeados), as inclinações partidárias dos participantes, bem como o eleitorado (local, estadual ou nacional) que está sendo representado.

Convém destacar que tanto a cooperação quanto a competição precisam ser bem dosadas para não comprometerem a autonomia de cada esfera governamental ou a interdependência entre elas. Por outro lado, também não se trata de negar essas características, mas buscar equilibrá-las em torno de objetivos comuns, da manutenção dos princípios federativos. Como propõe Wright (1988), os esforços passados para repensar o sistema intergovernamental têm sido repetidamente prejudicados pela incapacidade de se apreciar o fato de que, embora haja cooperação dentro do sistema, há também competição, conflito e mesmo coerção entre os vários níveis de governo. Assim, há uma necessidade óbvia de criação de um processo que facilite o reconhecimento da natureza complexa das relações intergovernamentais e permita o desenvolvimento de um núcleo de objetivos comuns.

Viu-se que está posto um desafio aos países federais, qual seja o de encontrar um caminho que proporcione o equilíbrio entre competição e cooperação, buscando nessas estratégias possibilidades de fortalecimento do sistema e de eliminação das disparidades. Tais questões remetem ao conceito de coordenação federativa discutido por autores como Abrúcio (2001; 2005), o qual utiliza o termo para destacar o inter-relacionamento entre os níveis de governo dentro do sistema federal. De acordo com o autor, o termo coordenação federativa diz respeito às "[...] formas de integração, compartilhamento e decisão conjunta presentes nas federações" (ABRÚCIO, 2005, p. 41).

De uma forma geral, para Ariznabarreta (2001), a coordenação pode geralmente ser definida como o processo de criação ou utilização de regras de decisão pelo qual dois ou mais atores ocupam coletivamente o mesmo campo. Ainda para a autora, a necessidade de coordenação surge da interdependência, ou seja, do fato de que duas unidades do mesmo ou de diferentes organismos compartilham o mesmo ambiente de trabalho. Ao relacionar esse conceito com os estudos realizados acerca do federalismo, observou-se que a coordenação é um elemento fundamental para o sucesso de uma organização política na qual a competência por uma determinada área é compartilhada por mais de um nível de governo, por exemplo, ou quando a interdependência é uma prerrogativa desse modelo de governo.

Para Abrúcio (2005), são possibilidades de coordenação federativa: as regras legais que obrigam os atores a compartilhar decisões e tarefas; os fóruns e mecanismos políticos de negociação intergovernamental; o funcionamento das instituições representativas; o papel coordenador e/ou indutor do governo federal.

Acerca da atuação do governo federal enquanto instrumento de coordenação federativa, concorda-se com Lotta, Golçalves e Bitelman (2014, p. 6) quando tratam da elaboração e execução de políticas no contexto brasileiro em conjunto com os demais entes:

embora a literatura apresente argumentos distintos para esse movimento [...], fala-se aqui de um movimento de fortalecimento do governo federal no sentido de coordenar políticas e diretrizes nacionais a serem implementadas pelos estados e municípios, considerando padrões comuns de ações e repasses de recursos a elas, além de incentivos e induções para a adesão dos entes às políticas desenhadas e coordenadas em nível federal. 
É nesse cenário de fortalecimento do governo central brasileiro no tocante à formulação de políticas a serem implementadas em conjunto com estados e municípios que se insere o Plano de Ações Articuladas.

\section{O Plano de Ações Articuladas no CONTEXTO DO FEDERALISMO BRASILEIRO}

O sistema educacional brasileiro tem primado por uma organização descentralizada da educação. No caso da educação básica, esse nível de ensino está organizado por 26 sistemas estaduais de educação, um distrital e 5.565 sistemas municipais, com autonomia para legislar e baixar normas. Essa diversidade de sistemas autônomos faz com que o atendimento educacional pelas distintas redes de ensino seja bastante diferenciado entre estas.

$\mathrm{Na}$ tentativa de minimizar as disparidades, o Art. 211 da Constituição Federal de 1988 institui para o campo educacional o regime de colaboração entre os entes federados e determina como competências da União as funções redistributiva e supletiva no tocante à educação, de modo a garantir a equalização de oportunidades e um padrão mínimo de qualidade mediante assistência técnica e financeira deste ente aos estados e municípios. O que pode ser considerado uma tentativa de efetivar o pacto federativo, haja vista que a transferência de recursos e assistência técnica se constituem numa das bases da cooperação no regime federalista.

Em 2007, o governo federal lançou o Plano de Desenvolvimento da Educação (PDE), cujo principal objetivo era melhorar a qualidade da educação brasileira em todos os níveis e modalidades, tendo como um de seus pilares de sustentação o regime de colaboração. O PDE foi divulgado à sociedade como a reunião de diversos programas e ações federais, alguns novos e outros já em funcionamento, tendo sido acrescentadas ao plano novas ações desde sua criação, em 2007.

O PDE é operacionalizado pelo Decreto Federal 6094, de 24 de abril de 2007. Denominado Plano de Metas Compromisso Todos pela Educação, o decreto fixa 28 diretrizes como metas para a melhoria da qualidade da educação a serem alcançadas de modo articulado com estados, Distrito Federal e municípios, junto com a participação das famílias e da comunidade. Ao assinarem o termo de adesão voluntária, previsto no Art. 4 o do decreto, os entes federados assumem a responsabilidade de implementar as diretrizes do Plano de Metas, visando a promover a melhoria da qualidade da educação básica em sua esfera de competência, a qual será aferida por meio da evolução do Índice de Desenvolvimento da Educação Básica - Ideb.

A assinatura do termo de adesão credencia municípios e estados a receberem apoio técnico e financeiro do
MEC. No tocante ao apoio financeiro, este se trata das transferências voluntárias da União, excetuando-se, portanto, as transferências decorrentes de determinação constitucional ou legal. Cabe destacar que qualquer transferência financeira voluntária do MEC aos municípios e estados, posterior ao lançamento do PDE, passa a estar condicionada à adesão do ente ao Plano de Metas.

Para receber o apoio da União, é necessária a elaboração do Plano de Ações Articuladas (PAR), previsto no Art. 9o do decreto. O plano é um "[...] conjunto articulado de ações, apoiado técnica ou financeiramente pelo Ministério da Educação, que visa o cumprimento das metas do Compromisso e a observância das suas diretrizes" (BRASIL, 2007). Ou seja, trata-se de um instrumento de planejamento e de gestão de caráter plurianual ${ }^{1}$ realizado pelos municípios e estados. O PAR envolve quatro dimensões do campo educacional: Gestão Educacional; Formação de Professores e Profissionais de Apoio Escolar; Prática Pedagógica e Avaliação; Infraestrutura. Cada dimensão é subdividida em áreas e indicadores.

$\mathrm{Na}$ construção do PAR, é necessário que as equipes técnicas dos municípios e estados, juntamente com o comitê local de acompanhamento do $\mathrm{PAR}^{2}$ e com o auxílio de uma consultoria disponibilizada pelo MEC, elaborem um diagnóstico de sua situação educacional, no qual são considerados os seguintes aspectos: dados demográficos e educacionais; dados dos dirigentes locais; questões pontuais sobre as quatro dimensões do PAR; entre outros. Essas informações são inseridas no Sistema Integrado de Monitoramento, Execução e Controle - Simec, o qual gera as ações que serão desenvolvidas, bem como aquelas que contarão com assistência técnica e financeira da União. Cabe ressaltar que tais ações são padronizadas e predeterminadas de acordo com a pontuação recebida para cada indicador de cada dimensão. Ou seja, pode ocorrer que em municípios de regiões distintas com realidades distintas sejam elencadas as mesmas ações. Em seguida, acontece a análise técnica do plano por parte da Secretaria de Educação Básica (SEB) do MEC e pelo Fundo Nacional de Desenvolvimento da Educação (FNDE). Após aprovado, é gerado o Termo de Cooperação Técnica que será firmado e assinado pelo ministro da Educação e pelo chefe do executivo local, constando as ações a serem executadas, bem como o comprometimento de ambas

\footnotetext{
${ }^{1}$ Municípios e estados elaboraram seus respectivos planos para o período de 2007 a 2011. Em 2011, um novo diagnóstico foi realizado, tendo sido elaborados novos planos para o período de 2011 a 2014.

2 Esse comitê deverá ser formado por dirigente municipal de educação; técnicos da Secretaria Municipal de Educação; representante dos diretores de escola; representante dos professores da zona urbana; representante dos professores da zona rural; representante dos coordenadores ou supervisores escolares; representante do quadro técnico-administrativo das escolas; representante dos conselhos escolares; representante do Conselho Municipal de Educação (quando houver) (BRASIL, 2011, p. 6).
} 
as partes de perseguirem as diretrizes estabelecidas no Decreto 6094/2007, visando à melhoria da qualidade da educação, mensurada pela elevação do Ideb.

A assistência técnica e financeira do MEC, que se consubstancia por meio da assinatura do Termo de Cooperação Técnica, faz parte das competências da União previstas no Art. 211 da Constituição Federal de 1988. É parte integrante, portanto, das responsabilidades ou competências governamentais da União, no setor da educação no Brasil, articulando-se a outras responsabilidades e à diretriz mais ampla de organização dos sistemas de ensino em regime de colaboração (FARENZENA, 2012).

Entretanto, no atual contexto, a adesão ao PAR tem sido o único meio de oferta de assistência técnica e financeira voluntária da União. Ou seja, no tocante à educação, os recursos federais que não se tratam das transferências obrigatórias da União aos demais entes só chegarão a esses mediante assinatura do termo. Conforme Oliveira (2009), não é de se estranhar que em 2008 todos os 26 estados e os 5.563 municípios houvessem aderido ao PAR.

Nesse sentido, convém destacar que governos federais, estaduais e municipais apresentam diferentes capacidades arrecadatórias e administrativas as quais podem significar o deslocamento do equilíbrio de poder nas arenas de tomadas de decisão (SANO, 2008). Assim, determinados governos, de modo especial o central, dada a arrecadação superior, podem utilizar-se do mecanismo de indução das políticas ao prestarem apoio tanto técnico quanto financeiro aos demais para implementação de uma determinada ação, como, por exemplo, o PAR, de modo que a cooperação, nesse caso, esteja atrelada a algum benefício recebido em troca.

\section{Plano de AÇões articuladas: INSTRUMENTO DE COLABORAÇÃO INTERGOVERNAMENTAL?}

A colaboração no sistema federativo recupera a noção de pacto, o qual se materializa na Constituição e em distintos momentos de acordo e negociação de políticas entre os governos. Mesmo havendo a separação de algumas funções governamentais entre os diferentes níveis de governos no regime federalista, nota-se a importância da colaboração intergovernamental já que cada vez mais a execução das políticas públicas é de competência partilhada, necessitando de um trabalho coordenado em sua implementação. Mesmo que no âmbito da organização da educação nacional haja divisão quanto às incumbências de cada ente, a legislação estabelece uma ação coordenada entre estados, municípios e União, visando ao desenvolvimento da educação básica, ou seja, estabelece que as relações intergovernamentais estejam fundadas na interdependência entre os entes federados.

$\mathrm{O}$ arranjo proposto para o campo educacional no tocante à oferta da escolarização obrigatória e a efetiva materialização do regime de colaboração requerem, portanto, relações intergovernamentais fundadas no modelo caracterizado por Wright (1988) como o de autoridade interdependente ou sobreposta. Só se efetivarão à medida que houver interação entre as unidades de governo com vistas à consecução de objetivos comuns, com áreas comuns de atuação e poderes e influências limitados.

Quanto à oferta de educação básica, pela leitura do Artigo 211 da CF, observou-se que existem áreas em que haverá atuação prioritária de determinado ente federado, mas também que existem áreas com atuação simultânea dos três entes governamentais, a qual deverá estar fundada na cooperação e na constante barganha e negociação entre as diferentes instâncias governamentais. Na tentativa de consolidar o regime de colaboração e buscando melhorar a qualidade da educação básica, o governo federal criou o Plano de Ações Articuladas, que está assentado na colaboração entre os entes, na busca por objetivos comuns.

Sobre a implementação do plano, considerando o contexto do federalismo brasileiro, é necessário fazer algumas ponderações. Uma delas diz respeito ao seu processo de elaboração. Ao organizar o PAR, as equipes locais puderam contar com a consultoria de uma equipe do MEC, principalmente naqueles municípios considerados prioritários por terem baixos resultados do Ideb. Conforme Ferreira (2014), para elaboração do primeiro PAR (20072011), tal consultoria aconteceu presencialmente, durante dois dias, e visou à elaboração do diagnóstico educacional e à avaliação de cada indicador previsto. Ferreira e Fonseca (2013), analisando os dados de pesquisa realizada sobre o PAR em municípios brasileiros, destacam como fator positivo a aproximação do MEC com as secretarias municipais, o que possibilitou maior interação entre os entes da federação e gerou estímulo e segurança aos municípios em relação à execução dos programas e planos federais. Além disso, a prática de elaborarem um diagnóstico da situação educacional pode ter contribuído para que muitos municípios buscassem conhecer e refletir sobre a própria realidade. O que pode também estimular a cultura do planejamento local.

A interação entre os funcionários das secretarias locais e do MEC revela um tipo de relação intergovernamental que se aproxima daquele modelo que Wright (1988) denomina de autoridade interdependente. E a relação com o modelo torna-se ainda mais acentuada quando se considera que o PAR se trata de um plano voltado para o campo educacional, área com significativas 
responsabilidades educacionais compartilhadas pelos entes da federação, única em que a legislação prevê um regime de colaboração para atuação conjunta por parte dos entes.

No entanto, mesmo observando que as relações intergovernamentais no tocante ao PAR estejam relacionadas com o modelo de autoridade interdependente, uma fragilidade observada no plano diz respeito às ações que podem ser executadas pelos municípios e estados a fim de alcançar a melhoria da qualidade da educação, mediante assistência técnica e/ou financeira voluntária da União. As possíveis ações geradas pelo Simec já são predeterminadas e não são passíveis de alteração por parte dos comitês locais, o que pode vir a comprometer a autonomia dos municípios, característica do federalismo brasileiro, uma vez que não há negociação ou barganha no sentido de alterar as ações de modo a atender com mais especificidade à realidade local de cada ente da federação.

Nesse sentido, para Camini (2010), a adesão ao plano, apesar de voluntária, pode ser considerada como um instrumento de subordinação dos estados, municípios e Distrito Federal à União, tendo em vista a dependência de muitos destes em relação à distribuição de recursos financeiros, bem como à prestação de assistência técnica da União. Ainda para a autora, é possível que esteja ocorrendo ingerência e permeabilidade políticoadministrativas de uma instância governamental sobre a outra, já que a União estaria exercendo influência no direcionamento de projetos e ações educacionais dos demais entes. A indução do plano e das ações nele contidas pode evidenciar relações intergovernamentais análogas ao modelo de autoridade inclusiva ou hierárquica, em que a atuação dos governos subnacionais depende das decisões tomadas pelo governo central.

Por outro lado, há que se fazer a ressalva de que a indução de ações como o PAR por parte do governo federal torna-se uma necessidade no caso brasileiro em razão da heterogeneidade presente no país. Nesse caso, a coordenação federativa exercida pela União ao induzir o plano pode ser considerada positiva, já que algumas das unidades subnacionais por si próprias não seriam capazes de planejar e executar ações que objetivassem superar as desigualdades educacionais, sendo necessária, portanto, a intervenção do governo central. Na compreensão de Ferreira, o PAR:

[...] é um instrumento de aplicação de diagnósticos e de organização racional das ações capazes de compensar a fragilidade operacional e política dos entes, o que justifica uma intervenção planejada pelo centro (FERREIRA, 2014, p. 619-620).

Dessa forma, destaca-se que, com o PAR, a União tem exercido o papel de promover a coordenação federativa no âmbito da educação, ao induzir o plano como uma política de governo que necessita da interdependência entre diferentes unidades de governo para sua execução. $\mathrm{O}$ inter-relacionamento visando à consecução de objetivos educacionais comuns, os quais podem ser observados na assessoria do MEC aos municípios e na assinatura do Termo de Cooperação Técnica, são elementos fundamentais para o combate às desigualdades regionais do país, de modo a alcançar equidade e assimetria no atendimento aos cidadãos.

No entanto, ao se considerar o caso do PAR, alguns mecanismos precisam ser reforçados, visando a aperfeiçoar as formas de integração, compartilhamento e decisão conjuntas presentes nas federações, ou seja, a coordenação federativa. Um deles seria o funcionamento de instituições representativas, o que no caso do PAR pode ser exemplificado por meio de seu comitê local de acompanhamento. Pesquisa realizada por Cunha, Costa e Araújo (2012) evidencia, no entanto, a fraca participação dos membros nesse comitê, ficando suas responsabilidades a cargo dos técnicos das Secretarias de Educação. Outro elemento seria a criação de espaços coletivos de tomada de decisão. Nesse sentido, cabe acrescentar que o PDE, plano que origina o PAR, foi criado pelo governo federal sem consulta e participação dos demais entes em sua fase de elaboração. Estados, distrito federal e municípios foram chamados a aderir ao PDE e ao Plano de Metas já preparado, para, a partir de então, elaborar seu PAR.

Outro elemento que merece atenção diz respeito ao fato de que, mesmo com a adesão ao PAR sendo feita por meio da assinatura de um termo no qual as duas partes firmam um compromisso em conjunto, é possível que apenas uma das partes assuma o ônus de efetivar as ações. Via de regra, apenas esta será cobrada diretamente pela elevação dos índices educacionais. De acordo com Ferreira e Fonseca (2013), na fase de execução das ações, a assistência técnica do MEC é traduzida por meio do controle permanente exercido via Simec, o qual pode ser diferenciado conforme a capacidade técnica e política de cada ente. Ainda de acordo com as autoras: "As ações e metas do PAR são executadas ou alteradas quando o FNDE as libera pelo Simec, pois, caso contrário, o município fica estático até o FNDE se pronunciar" (FERREIRA; FONSECA, 2013, p. 295). A afirmativa das autoras corrobora a ideia de que, embora o plano esteja fundado sob as bases da cooperação e colaboração entre os entes, o controle do sistema exercido pelo FNDE revela uma relação de subordinação do governo central para com os demais entes.

Nesse sentido, retoma-se a afirmação de Wright (1988) de que se faz necessário repensar o sistema intergovernamental, considerando não só a cooperação, mas também a competição, os conflitos e até mesmo 
a coerção entre os diferentes níveis de governo, elementos que podem existir mesmo em espaços em que predominem relações intergovernamentais fundadas no modelo de interdependência. Exemplos como o controle do Simec por parte do governo federal e a inércia dos municípios diante do referido controle demonstram que não há o reconhecimento mútuo da integridade de cada parceiro do pacto federativo, o que leva à necessidade de se buscar o equilíbrio das relações estabelecidas entre os diferentes níveis de governos, ainda mais em casos como o do Brasil, em que os milhares de municípios também são entes autônomos da federação. Dessa forma, estaria estabelecida a parceria e a partilha entre os governos que constituem a essência do federalismo, conforme destaca Elazar (1987).

Ressalta-se que mais importante do que o controle das ações executadas, seria o acompanhamento dessas ações por parte de uma equipe técnica qualificada na continuidade da assessoria técnica aos municípios durante a vigência dos planos, inclusive no tocante à utilização do Simec. Esse acompanhamento se torna ainda mais necessário em municípios de médio e pequeno porte, os quais, via de regra, sofrem com a precariedade administrativa e financeira, apresentam carência de recursos materiais e, sobretudo, insuficiência e despreparo de pessoas nas secretarias (FERREIRA; FONSECA, 2013). As dificuldades encontradas pelas Secretarias de Educação e equipes locais no tocante ao planejamento e execução do PAR reforçam a necessidade de existência de contatos e trocas entre os funcionários dos governos, característica do federalismo cooperativo.

Ao se encaminhar para a finalização deste texto, concorda-se com Araújo (2010) quando afirma que a indução de políticas como o PAR por parte da União se traduz mais como coordenação do que como colaboração. Isso porque a primeira se trata de um procedimento que busca resultado comum a partir da definição do governo central, e a segunda representa a tomada de decisões e o exercício das competências que devem ser conjuntas e não isoladas.

Assim, embora com o PAR, por um lado, a União esteja cumprindo em parte sua função redistributiva e supletiva à medida que financia ações nos municípios e estados; por outro lado, ela tem determinado o que deve ser feito e como deve ser feito a fim de alcançar as metas estabelecidas por este ente sem existência de diálogo profícuo com os demais. O que se observa, entretanto, é que não se trata de uma relação hierárquica de subordinação de municípios e estados diante da União, já que esta dispõe de poder para muitas decisões, mas não controla todas, sendo aqueles entes autônomos para aderir ou não às políticas (ARAÚJO, 2010). Identificase, portanto, o deslocamento da arena decisória em que a União assume não só a coordenação federativa em termos de políticas educacionais, mas também a indução de programas e metas.

\section{CONSIDERAÇÕES FINAIS}

A educação básica nacional está organizada sob o pressuposto da colaboração entre União, estados, distrito federal e municípios, com competências educacionais exclusivas para cada um destes e para outras compartilhadas. Essa perspectiva está fundada no federalismo cooperativo, o qual prevê a autonomia e a interdependência entre os níveis de governo, bem como uma inter-relação de colaboração entre estes.

A CF de 1988 institui o regime de colaboração para a educação e determina as competências e responsabilidades de cada ente no que diz respeito a essa área. No entanto, passados mais de 20 anos da aprovação da Constituição, o regime de colaboração ainda não conseguiu ser efetivado no Brasil. A mais recente tentativa nesse sentido por parte da União diz respeito ao Plano de Desenvolvimento da Educação/Compromisso Todos pela Educação, o qual advoga a melhoria da educação em regime de colaboração com municípios, Distrito Federal e estados, e a participação das famílias e da comunidade. A colaboração prevista no PDE, no compromisso e, por conseguinte, no PAR, no entanto, traduz-se mais como ações de coordenação federativa por parte do governo federal, ou, como afirmam Oliveira e Sousa (2010, p. 28), trata-se de uma "colaboração" que vem do centro.

No Caso do PAR, alguns aspectos discutidos ao longo do texto evidenciam que o plano não está em conformidade com o federalismo cooperativo. Um deles diz respeito à possibilidade de tomada de decisões por parte de alguns entes federados, aspecto que é subsumido pela execução de tarefas cujas decisões foram tomadas pelo governo central, demonstrando assim um processo de desconcentração.

$O$ fato de as ações do PAR não poderem sofrer alterações de acordo com a realidade local e suas execuções estarem condicionadas à liberação do FNDE/MEC são alguns dos exemplos que evidenciam o controle e a centralização da União. Tal postura do governo central não condiz com a dupla soberania necessária ao federalismo, a dos governos subnacionais e a do governo central, muito menos com a existência de múltiplos centros de poder. Além disso, a pouca participação nos comitês locais, bem como a inexistência de mecanismos de articulação intergovernamental, tais como fóruns de negociação, são algumas das fragilidades observadas no PAR no que diz respeito à efetivação do pacto federativo.

É necessário reconhecer a relevância do plano no que diz respeito ao seu objetivo principal, de melhorar 
a qualidade da educação básica por meio de uma visão sistêmica de educação, a qual envolve a atuação conjunta das esferas governamentais. Além disso, o interrelacionamento das equipes do MEC com as secretarias locais favoreceu a interação entre os entes da federação, bem como gerou segurança aos municípios em relação à execução dos programas e planos federais e do próprio planejamento local. Outro aspecto positivo é que, com a indução do PAR, o governo federal tem exercido a coordenação federativa e buscado integrar as ações na nação, o que pode vir a fortalecer o sistema federativo brasileiro.

Entretanto, a coordenação federativa ainda precisa avançar quanto ao compartilhamento da tomada de decisões, bem como quanto à criação e efetivação de fóruns e mecanismos políticos de negociação intergovernamental e ao funcionamento das instituições representativas. Ainda que o PAR tenha em sua estrutura relações intergovernamentais fundadas na interdependência entre os entes federados e que a autonomia de estados e municípios tenha sido respeitada em sua totalidade no tocante à adesão ao plano - mas parcialmente no que concerne às metas e ações previstas -, não se pode afirmar que o PAR por si só seja capaz de efetivar a colaboração intergovernamental prevista para o campo educacional. Isso porque a colaboração vai mais além da coordenação ao requerer que todos os entes tomem decisões e atuem em conjunto.

\section{REFERÊNCIAS}

ABRUCIO, Fernando Luiz. A dinâmica federativa da educação brasileira: diagnóstico e propostas de aperfeiçoamento. In: OLIVEIRA, Romualdo Portela de; SANTANA, Wagner (Org.). Educação e federalismo no Brasil: combater as desigualdades, garantir a diversidade. Brasília: Unesco, 2010.

ABRUCIO, Fernando Luiz. A coordenação federativa no Brasil: a experiência do período FHC e os desafios do governo Lula. Revista de Sociologia Política, Curitiba, v. 24, p. 105-121, jun. 2005.

ARAÚJO, Gilda Cardoso. Direito à educação básica: a cooperação entre os entes federados. Retratos da Escola, Brasília, v. 4, n. 7, p. 231-243, jul./dez. 2010.

ARIZNABARRETA, Koldo Echebarria. Capital social, cultura organizativa y transversalidad en la gestion pública. In: CONGRESO INTERNACIONAL DEL CLAD SOBRE LA REFORMA DEL ESTADO Y LAADMINISTRACIÓN PÚBLICA, VI., 2001, Buenos Aires. Anais... Buenos Aires, 5 a 9 nov. 2001.

BRASIL. Decreto no 6.094, de 24 de abril de 2007. Dispõe sobre a implementação do Plano de Metas Compromisso Todos pela Educação. Disponível em: <http://www.planalto.gov.br/ ccivil_03/Ato2007-2010/2007/Decreto/D6094.htm>. Acesso em: $2 \overline{1}$ mar. 2016.

BRASIL. Guia Prático de Ações. Brasília, 2011. Disponível em: <http://portal.mec.gov.br/arquivos/pdf/guia_de_acoes. pdf/>. Acesso em: 21 de mar de 2016.
CAMINI, Lucia. A política educacional do PDE e do Plano de Metas Compromisso Todos pela Educação. RBPAE, v. 26, n. 3, p. 535-550, set./dez. 2010.

CUNHA, Maria Couto; COSTA, Jean Mário Araújo; ARAÚJO, Rosemeire Baraúna Meire de. O Plano de Ações Articuladas: percepções e expectativas na gestão da educação municipal. Série Estudos - Periódico do Programa de Pós-Graduação em Educação da UCDB, n. 34, jul./dez. 2012.

ELAZAR, Daniel J. Exploring Federalism. Tuscaloosa: The University of Alabama Press, 1987.

FARENZENA, Nalú. A implementação de Planos de Ações Articuladas municipais: marcos e trajetórias de uma pesquisa de avaliação. In: FARENZENA, Nalú (Org.). Implementação de Planos de Ações Articuladas Municipais: uma avaliação em quatro estados brasileiros. Pelotas: Ed. Universitária da UFPel, 2012.

FERREIRA, Eliza Bartolozzi. Federalismo e planejamento educacional no exercício do PAR. Cadernos de Pesquisa, v. 44, n. 153, p. 602-623, jul./set. 2014.

FERREIRA, Eliza Bartolozzi; FONSECA, Marília. Plano de Ações Articuladas (PAR): discutindo dados da pesquisa em rede. In: FERREIRA, Eliza Bartolozzi; FONSECA, Marília (Org.). Política e planejamento educacional no Brasil do século 21. Brasília: Liber Livro, 2013.

FRANZENE, Cibele. Federalismo cooperativo no Brasil: da Constituição de 1988 aos sistemas de políticas públicas. 2010. 210 f. Tese (Doutorado) - Escola de Administração de Empresas de São Paulo, Fundação Getúlio Vargas, São Paulo, 2010.

GRODZINS, Morton. The American System. Chicago: Rand McNally, 1966.

LOTTA, Gabriela Spanghero; GONÇALVES, Renata; BITELMAN, Marina. A coordenação federativa de políticas públicas: uma análise das políticas brasileiras nas últimas décadas. Cadernos Gestão Pública e Cidadania, São Paulo, v. 19, n. 64, jan./jun. 2014.

OLIVEIRA, Dalila Andrade. As políticas educacionais no governo Lula: rupturas e permanências. RBPAE, v. 25, n. 2, p. 197-209, maio/ago. 2009.

OLIVEIRA, Romualdo Portela de; SOUSA, Sandra Zákia. Introdução. In: OLIVEIRA, Romualdo Portela de; SANTANA, Wagner (Org.). Educação e federalismo no Brasil: combater as desigualdades, garantir a diversidade. Brasília: Unesco, 2010.

SANO, Hironobu. Articulação horizontal no federalismo brasileiro: os Conselhos de Secretários Estaduais. 2008. $308 \mathrm{f}$. Tese (Doutorado em Administração Pública e Governo) - Fundação Getúlio Vargas, Escola de Administração de Empresas de São Paulo, São Paulo, 2008.

SOUZA, Celina. Federalismo: teorias e conceitos revisitados. Revista Brasileira de Informação Bibliográfica em Ciências Sociais, São Paulo, n. 55, p. 27-48, 2008.

WRIGHT, Deil S. Understanding intergovernmental relations. 3. ed. California: Books/Cole Publishing Company, 1988.

Recebido em: 08-04-2016. Aprovado em: 18-05-2017. 